\title{
Reporting adverse drug reactions in HIV infection
}

An increasing number of new drugs is becoming available for the treatment of individuals infected with HIV, and their use in combination is resulting in improvements in morbidity and mortality. ${ }^{1}$ Several of the new drugs were licensed on the basis of clinical trials studying small numbers of patients which were designed to show changes in surrogate markers of disease. ${ }^{1}$ Therefore, at the time of licensing, only limited data were available on their safety. ${ }^{23}$ Once marketed, the use of a medicine is very different from the clinical trial situation; the patient population becomes more heterogeneous and different doses and combinations of drugs may be used. ${ }^{4}$ For these reasons, new adverse reactions, including interactions, will inevitably come to light after drugs are marketed. ${ }^{4}$

The yellow card scheme was launched over 30 years ago and has been crucially important in monitoring drug safety in routine clinical practice, increasing knowledge about known adverse drug reactions, and acting as an early warning system for the identification of previously unrecognised adverse reactions. Between July 1996 and July 1997 only 91 reports were received in the United Kingdom, by the scheme, for all anti-HIV drugs. During this time spontaneous reporting outside the United Kingdom identified a number of important adverse reactions, including the occurrence of haemolysis among patients treated with indinavir (Crixivan), and of diabetes mellitus and hyperglycaemia among patients treated with all of the protease inhibitors.

In order to maximise our understanding of the safety of drugs used in HIV infection, the MRC HIV Clinical Trials Centre, in collaboration with the Medicines Control Agency (MCA) and Committee on Safety of Medicines (CSM), is launching a scheme specifically for doctors and pharmacists caring for individuals with HIV infection. The scheme will complement the existing yel- low card scheme, and, like the yellow card scheme and data from participants in MRC trials, reports will be handled in strict confidence. Individual reports and case series will be analysed jointly by the MRC, MCA, and CSM, the combined expertise maximising the benefits of the scheme. Changes in the balance of risks and benefits of drugs, as well as newly identified adverse reactions will be fed back to those caring for individuals with HIV infection through the MRC HIV Clinical Trials Centre newsletter and in a new newsletter HIV ADR Reporting Scheme News.

Reporting suspected adverse drug reactions through the HIV Adverse Drug Reaction Reporting Scheme will allow information about drug safety to be disseminated to help reduce the morbidity and mortality associated with HIV infection.

Medical Assessor

P R ARLETT

Medicines Control Agency

Head, Pharmacovigilance Evaluation Unit Medicines Control Agency

E H LEE

Trial Physician Co-ordinator

MRC HIV Clinical Trials Centre

Head, MRC HIV Clinical Trials Centre

J H DARBYSHIRE

A M BRECKENRIDGE

\section{Chairman, MRC AIDS Therapeutic}

Trials Committee

1 BHIVA Guidelines Co-ordinating Committee. British HIV Association guidelines for anti-retroviral treatment of HIV seropositive individuals. Lancet 1997;349:1086-92.

2 Heylen R, Miller R. Adverse effects and drug interactions of medications commonly used in the treatment of adult HIV positive patients. commonly used in the treatm

3 Heylen R, Miller R. Adverse effects and drug interactions of medications commonly used in the treatment of adult HIV positive patients: Part 2. Genitourin Med 1997;73:5-11.

4 Waller PC, Coulson RA, Wood SM. Regulatory pharmacovigilance in the United Kingdom: current principles and practice. Pharmacoepidemiol Drug Safety 1996;5:363-75. 